\title{
Study on Creative Design of Bamboo Furniture from the Perspective of Ecological Design*
}

\author{
Weixia Gao \\ School of Art \&Garments Engineering \\ Changshu Institute of Technology \\ Changshu, China 215500
}

\begin{abstract}
This paper deals with the innovative design and strategy of bamboo furniture from the perspective of ecological design. Firstly, it introduces the background and concept of bamboo furniture ecological design. Secondly, it analyzes three aspects of bamboo furniture ecological design, including material, technic and culture. Finally it explores effective bamboo furniture ecological design strategies based on product life cycle theory. It is expected to build a new idea for the bamboo furniture.
\end{abstract}

Keywords-creative design; bamboo furniture; ecological design

\section{INTRODUCTION}

Facing various threats to sustainable human survival, such as global warming, water crisis, and so on, the concept of ecological design is born. It is a comprehensive design model based on the economic, ecological, and social multiparty standards through the design of material and services to adapt to the principle of sustainable development of population, economic and social resources and ecological environment. The goal is to reduce the adverse effects on the environment, realize the harmony between man and nature coexist [1]. Material is an important content in the process of ecological design, and its selection directly affects the design, process, quality and life cycle of the product. Bamboo as an environmentally friendly material has been favored by people since ancient times [2]. There is much traditional bamboo furniture such as chairs, stools still in use. The current bamboo furniture design field generally lacks of ecological design, sustainable design consciousness, which also remains in the direct use of traditional bamboo and has not yet been discussed in other aspects.

\section{The ECOlOGICAL Design CASES OF BAMBOO FURNITURE}

\section{A. Application of Ecological Materials}

China is one of the most abundant bamboo resource countries in the world, and has a long history of cultivation and utilization. The characteristics of bamboo materials have a great influence on furniture design. For example, it can be

*This work was financially supported by Research Project of Changshu Institute of Technology (KYZ2017103Z) used for modeling design by utilizing its bending characteristics. In addition, bamboo integrated material, a new material now the furniture manufacturing industry is respected, is the rectangular bamboo with certain sizes, after treatment of anti-corrosion, mildew, moth, drying and gluing process which can make furniture more lightweight and smooth in the overall modeling, and realize modular furniture design, making furniture design more diversified, so as to achieve ecological design.

Professor Haoming Zhou's design team works "Portable folding bamboo chair", as shown in "Fig. 1", from Academy of Arts Design, Tsinghua University with ecological features that the main materials is the environmental protection materials widely respected by the international design community in recent years - bamboo plywood and linen. These two materials belong to the fast-growing plant, and when they are abandoned, they can also be degraded quickly and naturally, thus reducing the damage to the natural environment. Its design inspiration comes from the traditional works of Chinese spot and campstool. By optimizing the force structure and construction mode, the chair's component is simplified to 3 rectangular frames, 1 flax linens and 4 metal screws. The chair is detachable and foldable, and the operation is simple and easy to replace the damaged component. The folded chairs have very little space to move and carry, and to save the cost of transportation and storage.

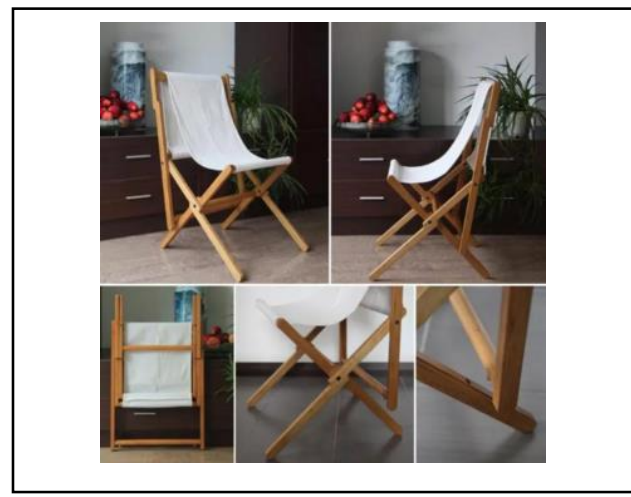

Fig. 1. Portable folding bamboo chair.

\section{B. Use of Sustainable Technics}

Bamboo handicrafts refer to the process through the aesthetic treatment of the external form to make the daily 
necessities and ornaments, including bamboo carving, bamboo weaving and other skills [3]. Take the bamboo weaving process as an example, the bamboo materials of different regions and varieties brought different styles and effects in different parts of the country, such as bamboo of the lower reaches of the Yangtze River is hard, but good elasticity, suitable for making practical rough editing artifacts, while Sichuan bamboo soft, suitable for the preparation of fine porcelain, is a good material bamboo over porcelain. The combination of traditional handicraft and modern design method is the design trends, such as a named "43" cantilever chair shown in "Fig. 2", is jointly designed by German fashion designer Konstantin Grcic and Taiwan bamboo master Gaoming Chen. With the characteristic of Taiwan moso bamboo as raw material, and compiled by 43 pieces of bamboo, each piece is bent into a different angle to present the natural curve of the chair when it carries the body.

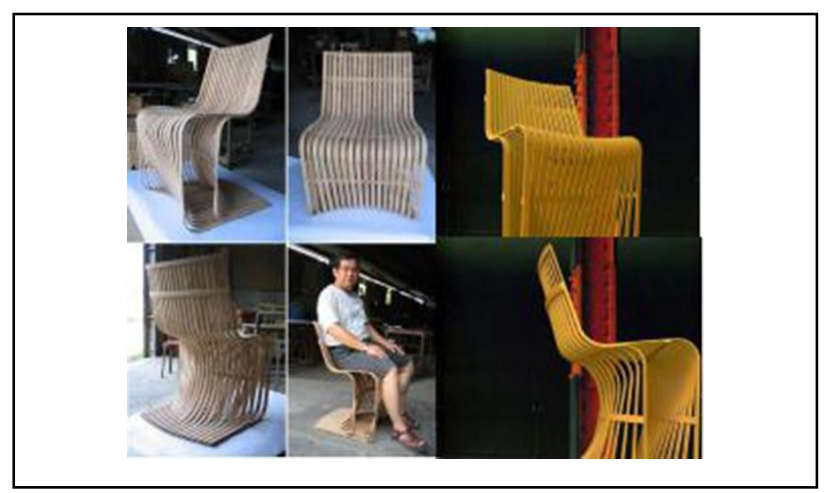

Fig. 2. Cantilever bamboo chair-43.

\section{The Ecological Continuation of Culture}

Bamboo is closely related to people's life in China, penetrated into all aspects of basic necessities of life in the long process of historical development. In the Chinese culture, bamboo is far from a purely biological sense, but a "humanized" nature, which is the unique emotion concept and ideal of the Chinese nation. On the one hand, it conveys the aesthetic taste of the Chinese nation, the spirit of religion, the ideal of personality through the calligraphy and painting, the garden architecture and so on. On the other hand, it unconsciously and spontaneously shows the spiritual world of the Chinese nation through tangible things such as the use and rules of bamboo production, daily necessities and so on [4].

From the point of view of design, culture is the soul of design. In the same way, the soul of the design of bamboo furniture is its implicit bamboo culture. For example, the bamboo mosaic series shadow table as shown in "Fig. 3" is a typical case which combines the traditional bamboo cultural symbols and modern design elements to give a profound culture to the product. The side table is composed of a detachable metal bracket and a tray desktop. The clever design allows it to be portable, and the desktop pallet is also used separately. The thin frame structure is clear and transparent, and any corner of the space will not obstruct the sight and have the right sense of existence. The simple and modern side table is inspired by the traditional wooden washbasin rack. The bamboo silk inlay tray has the shadow of the bamboo steamer with the life breath and emotional memory, which makes this lightweight contemporary furniture implicitly and classical.

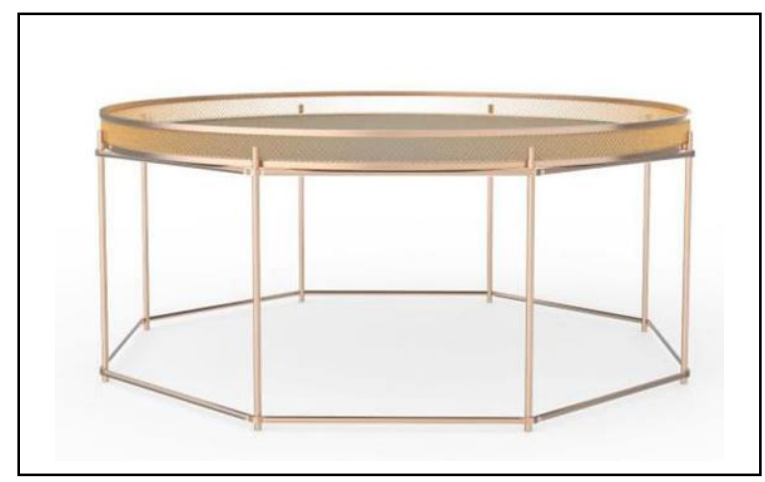

Fig. 3. The bamboo mosaic series shadow table.

Throughout history, love bamboo is almost a common cultural value of Chinese people. Bamboo is praised for green and flourish all through the year, whether storm or snow and has been endowed with a good reputation as a "gentleman"[4]. Jeff Dayu Shi, a designer in Taiwan, has extended the exploration of life style guided by bamboo to the deeper spiritual realm. He designed the "gentleman chair" with a simple geometric figure to outline the seat structure and comfortableness as shown in "Fig. 4". The chair seat is made of bamboo strips, forming a square box arrangement, and looks like a tunnel composed of bamboo rings from the front side. The chair back adopts the same structure and the overall profile of the side resembles the shape of the Chinese character "Yin". The chair surface is made up of lines and elegant bamboo strips. When it is loaded, it shows delicate elasticity like string. When sitting down, you can feel the strong and smart vitality of bamboo. To sum up, the design of this chair not only preserves the excellent characteristics of the bamboo itself, such as toughness and strength, but also enhances the practicability of the design. Meanwhile, it uses the bamboo material to blend the connotation of "gentleman" in the bamboo culture skillfully.

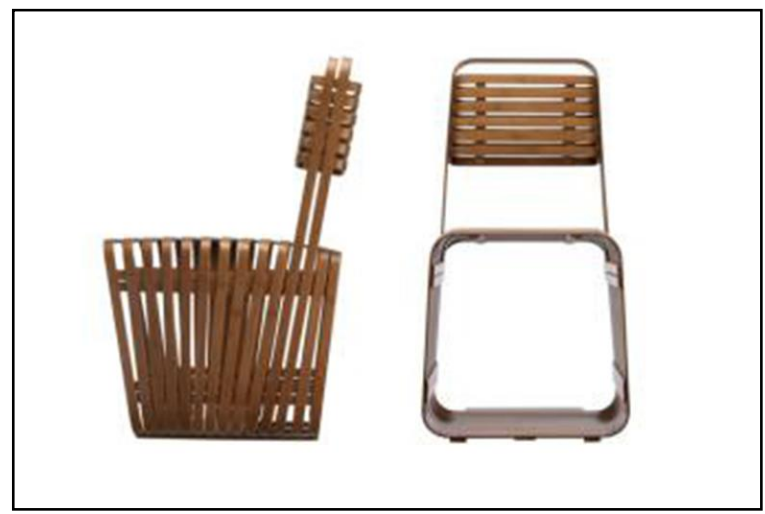

Fig. 4. The gentleman chair.

\section{The ECOlogicAl Design StRATEgIES OF BAMBoO FURNITURE}

Early design, material selection, production process, longterm use and simple maintenance, warehousing, transportation and recycling play an important role in the life cycle of bamboo 
furniture products. At the same time, with the globalization of the market and the continuous growth of online shopping, the form of products and the way of packaging and transportation must also be changed. This has become an important issue to be concerned about the ecological design of bamboo furniture [5].

The ecological development in design refers to the design development strategy that combines the current interests, longterm interests, personal interests and social interests of design activities. Ecological design principles for bamboo furniture industry, means for the minimum consumption of energy and resources minimize the burden for nature. The ecological design strategy of bamboo furniture is to put forward the problems which should be considered in the life cycle design of bamboo furniture and the ideas to solve the problem [6].

\section{A. Conceptual Development Stage}

- Low materialization. Bamboo furniture products tend to be smaller and lighter in weight. Through technological innovation, institutional reform and behavior inducement, we can reduce the input of material resources in the process of social production and consumption under the premise of guaranteeing the quality of bamboo furniture production and consumption.

- Sharing of products. When many people share a product, the use efficiency of the product can be greatly improved. The sharing of transportation tools is a very successful case in China. In fact, there are many products that can be shared in real life, and bamboo furniture is no exception. On the one hand, we should consider the development of new forms of bamboo furniture for sharing. On the other hand, we also should consider how to improve the sharing rate of existing bamboo furniture products. The benefit of bamboo furniture products share is to improve the product use efficiency, reduce material and energy consumption, reduce the transportation cost, force manufacturers to track and serve the use and post processing of products.

\section{B. Design Stage}

- Function optimization. When the main functions and auxiliary functions of bamboo furniture products are considered as a whole, the auxiliary functions of the products can be improved and less consumed. First of all, the optimization of products needs to analyze consumer demand for furniture of main function and auxiliary function, and determine whether the organic unity of the two. Secondly, it is necessary to analyze the manufacturing costs of products, including raw materials, processes, assembly, labor and operating costs to optimize the cost. Finally, it is necessary to combine the two to consider whether the maximum function can be achieved with the minimum cost.
- Modular design. The modular design method of bamboo furniture product can maximize the renewability of the product to meet the changing needs of user. For example, the replacement of the surface of the surface makes it often new, or the vulnerable parts are integrated into a complete module, which can be replaced once in one time.

\section{The Post Use Stage}

- Structural disassembly. Bamboo furniture design should consider the disassembly of products to help to reuse products, recycle raw materials and promote the recovery of products. In addition, a detachable connection and a standardized connection can be used as much as possible, and the product design instructions should also show how to assemble them.

- Remanufacture. We should consider reusing the valuable components of the products, and recycle the raw materials after being scrapped. They can be recycled according to the original level of use, and can also be recycled after processing. Priority is given to the first form of recycling.

\section{CONCLUSION}

Bamboo furniture design based on the concept of sustainable design requires designers to study the bamboo material characteristic and rich cultural heritage. It should be considered as a whole from the life cycle of the product to a higher strategic level.

\section{REFERENCES}

[1] Yanliuxing Yan. Research on modern furniture design based on design for sustainability(Shanghai Jiao Tong University, Shanghai 2010).

[2] Weifeng Zhao. Application of Bamboo Material in Interior Design (Central South University of Forestry and Technology,Changsha 2006).

[3] Jiali Pei, Yang Wang. The application and inheritance of the traditional bamboo craft in the packaging design of the south of the Yangtze River. Art Education, Vol.4, pp.203-204,February 2014.

[4] Yongqian Zou. A cultural interpretation of bamboo China, Sichuan University press, 2014.

[5] L.Dong, H.Zhang and Y.Wang. Research on sustainable strategies for the research and development of architectural products in the era of industrialization, Architecture and Culture, Vol.2, 2015,pp.104-105.

[6] Jian Yang. Product life cycle evaluation method and application, Meteorological Press, 2002. 